splitting of the finger-nails provided me with a clue to the diagnosis in these cases. The coexistence of nail changes and a raised serum uric acid in 19 cases would appear to suggest that reeding and splitting and brittleness, either individually or together, may be a frequent physical sign in hyperuricaemia and might warrant further investigation.-I am, etc.,

Casino Memorial Hospital,
New South Wales, Australia

\section{Detection of Hyperparathyroidism}

SIR,-The most important biochemical finding in the detection of hyperparathyroidism is a raised plasma calcium level. However, in the differential diagnosis from other forms of hypercalcaemia additional biochemical findings are necessary. The following case report points to the plasma chloride level and so may be of interest.

A woman age 35 years with a history of renal calculi four years and seven years previously, and whose serum calcium was 12.9 and 11.9 $\mathrm{mg} . / 100 \mathrm{ml}$. and inorganic phosphate 2.05 and $2.5 \mathrm{mg} . / 100 \mathrm{ml}$. with normal alkaline phosphatase (13.8 and 14.4 K.A. units), was admitted for further investigation in March 1968. For about $2 \frac{1}{2}$ years she had had dyspnoea on moderate exertion, pain in her left upper arm, and paraesthesiae of the fingers of her left hand. More recently she had been feeling irritable with marked tiredness, loss of energy, loss of weight, and blurring of vision.

Physical examination of this healthy looking female with a pulse rate of 80 and B.P. 150/90 was normal. Full blood count, E.S.R., blood urea, $x$-ray of chest, skull, hands, and barium swallow were also normal. Urine specific gravity was 1017 and reaction acid. Serum sodium and potassium were normal, but serum chloride was elevated to 115,120 , and $121.5 \mathrm{mEq} / 1$. In a specimen of arterial blood the $\mathrm{pH}$ was 7.36 , bicarbonate $22.8 \mathrm{mEq} / \mathrm{l}$., and $\mathrm{PCO}_{2} 43 \mathrm{~mm}$. of mercury. Serum calcium was $12.6 \mathrm{mg} . / 100 \mathrm{ml}$., inorganic phosphate $2.4 \mathrm{mg}$. $/ 100 \mathrm{ml}$., and alkaline phosphatase 12.3 King-Armstrong units. The E.C.G. showed a shortened QT interval $(0.36$ second) compatible with hypercalcaemia.

Because of the progressive symptoms with the persistently raised serum calcium, lowered inorganic phosphate, and the hyperchloraemia, the neck was explored, and a parathyroid adenoma, proved by histology, was removed on 14 March. Post-operative progress was satisfactory and her serum calcium was 9.7 and $9.8 \mathrm{mg} . / 100 \mathrm{ml}$. on the first and fourth postoperative days. On this latter day the serum inorganic phosphate was $3.2 \mathrm{mg} . / 100 \mathrm{ml}$., and alkaline phosphatase 10.9 King-Armstrong units. Serum chloride decreased post-operatively and was 109,102 , and $104 \mathrm{mEq} / \mathrm{l}$. on the first, second, and fourth postoperative days; other serum electrolytes $(\mathrm{Na}$ and $K$ ) remained normal.

At follow-up one year postoperatively (April 1969) the patient was very well and her symptoms had disappeared. Her plasma calcium was $9.7 \mathrm{mg} . / 100 \mathrm{ml}$. and her plasma chloride $107 \mathrm{mEq} / 1$.

The plasma inorganic phosphate level is the additional biochemical finding generally thought to be of value in the differential diagnosis of hyperparathyroidism from other forms of hypercalcaemia. According to Thomas, Connor, and Morgan ${ }^{1}$ and Howard ${ }^{2}$ the plasma bicarbonate might be useful Wills and McGowan ${ }^{3}$ found that 32 of their 33 patients with proved primary hyperparathyroidism had plasma chloride levels of not less than $102 \mathrm{mEq} / \mathrm{l}$. Furthermore, they belieyed that the plasma chloride level was superior to the plasma inorganic phosphate level for differentiating hyperparathyroidism from other conditions associated with hypercalcaemia.

This case report shows that an elevated plasma chloride level may be of value in the differential diagnosis of primary hyperparathyroidism.-We are, etc.,

ANDREW HEFFERNAN. HELEN CARTY.

Mater Misericordiae Hospital.

$$
\text { Dublin } 7 . \quad \text { REFERENCBS }
$$

${ }^{1}$ Thomas, $W_{\dot{q}}$ C., Connor, T. B., and Morgan, H. G., fournal of Labor.

Modicine. 1958, 52,11 ransactions of the College of Physicians of Philadelphia, 1962, 30, 55 . Medical fournal, 1964, 1, 1153 .

\section{Abortion Act Amendment}

SIR,-I would like to draw the attention of general practitioners to the rather subtle attack on their status implied in the recent failed amendment, and the lobbying and manœuvring continuing now, in connexion with the Abortion Act.

The Act as it stands simply requires the opinion of two doctors, who may therefore be general practitioners. While claiming that there is no suggestion that any general practitioner be excluded from assessing that an abortion is necessary or desirable, what is being sought by the opponents of the Act in its present form is that one of the two doctors should be a consultant gynaecologist holding office in the N.H.S.

What this seemingly innocuous and apparently sensible suggestion amounts to in fact is a despicable attack on the competence of " the other" general practitioner to make the relatively simple obstetric assessment necessary and give the second opinion required by the Act. By restricting the operation of the Act to a minority of the profession, many of whom are opposed to it on religious and other grounds, will cripple it. Furthermore, I think it should be pointed out that, with the Act as it is at present, the gynaecologist who carries out the termination provides a third safeguard, if that is necessary.

I hope this threat to the Act and attack on the status of the general practitioner will be noted and acted upon by those concerned. -I am, etc.,

London N.W.3.

Norman ChIsholm.

\section{Elbow Disorders}

SIR,-In his article on the elbow joint (16 August, p. 399) Dr. Malcolm Thompson refers to the possible origin of pain felt in the upper limb being in the cervical spine, especially when the pain is diffuse, with no localized tender points. I should like to draw attention to two causes of typical "tennis" or "golfer's" elbow, in which the cause is proximal, but in which there is well-localized tenderness and pain, because they frequently lead to failure of the usual treatment or to repeated relapse.

The first cause lies in the cervical spine, either as the common "stuck neck" with cervical discomfort and limitation of movement, but with normal $x$-ray findings, or as cervical spondylosis, often mild ; in either case symp- toms and signs in the neck may be minimal. In the first case manipulation of the neck produces a click and restores full movement with relief of the elbow pain sometimes in a few minutes, but more frequently within a few days ; in the second case the usual treatments of cervical spondylosis, such as a sof collar, traction, and mobilizing exercises, and in selected cases gentle manipulation, produce relief.

The other, and more rare, cause of treatment-resistant tennis or golfer's elbow is a lesion of the acromioclavicular or occasionally sternoclavicular joint, or both Again, this area may be virtually symptomfree, or there may be some discomfort in the shoulder, specially at the extremes of elevation, external rotation, or adduction of the arm. The affected joint is invariably tender to pressure. The cause of the lesion may be trauma, often minor, such as a fall or a jerk, or unaccustomed work-for example, gardening or carrying heavy cases on holiday occasionally it is found to be early and sometimes previously undiagnosed rheumatoid arthritis. The elbow pain is sometimes improved dramatically following the injection of steroid with or without local anaesthetic into the tender joint; the total quantity injected should be less than $1 \mathrm{ml}$. to reduce the risk of a temporary increase in the pain owing to distension of the joint.-I am, etc.,

\section{G. H. UNGAR}

National Spinal Injuries Centre.
Sitoke Mandeville Hospital,

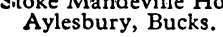

SIR,-I should like to congratulate Dr. Malcolm Thompson on his excellent article on the elbow (16 August, p. 399). He stresses the importance of making certain that the patient is not suffering from gout, which applies equally to the female sex over the age of 50 .

I should like to emphasize the question of strain of the forearm extensors in tennis elbow. The tender points are over the lateral epicondyle and the radio-humeral ligament which constitute the origin of the extensors. However, in the action of producing the forearm stroke or similar movements, as the dentist extracting molar teeth, the hand starts from the pronated position and goes to the suipinated position with the elbow slightly flexed. Gradually, therefore, in tennis elbow the radio-humeral joint becomes involved, and, as Winchester ${ }^{2}$ has shown, marked degenerative changes may occur in the head of the radius and the corresponding articular surface of the lower end of the humerus in patients with this condition as early as the age of 30 . The biceps muscle is the main flexor of the elbow and supinator of the forearm, and becomes involved in almost all cases of tennis elbow. This is shown by tenderness in relation to the long head of biceps in the front of the shoulder.

Golfer's elbow is a similar condition in which, however, the movement takes place with the pain starting from the supinated position and going to the pronated position. The flexors and the pronator radii teres are activated and the biceps can still be involved because the elbow is always held slightly flexed.

My opinion is that many of these strains are the result of faulty head-neck-shoulder 